\title{
Digital Photography - A New Perspective in Modern Dental Practice
}

Dr. Parul Sharma ${ }^{1}$, Dr. Shubh Karmanjit Singh Bawa ${ }^{1 *}$, Vidushi Jindal ${ }^{2}$, Dr. Vikas Jindal ${ }^{1}$, Dr. Divye Malhotra ${ }^{3}$, Dr. Ramneek Bansal $^{3}$, Dr. Shamsher Sandlas ${ }^{4}$, Dr. Pankaj Chauhan ${ }^{1}$

${ }^{1}$ Department of Periodontics \& Implantology, Himachal Dental College, Sundernagar

${ }^{2} 3$ rd Year Student, Universida Católica San Antonio (UCAM, Murcia, Spain)

${ }^{3}$ Department of Oral \& Maxillofacial Surgery, Himachal Dental College, Sundernagar

${ }^{4}$ D.M.D, University of British Columbia,Vancouver. Canada

DOI: $10.36347 /$ sjds.2020.v07i09.002

| Received: 25.08.2020 | Accepted: 02.09.2020 | Published: 17.09.2020

*Corresponding author: Dr. Shubh Karmanjit Singh Bawa

Abstract

What if we tell you that there is a simple, yet a highly effective method that it can be used not only to document the work done but also, teach the students, promote the dental practice and inform the patients using visualization methods? We are talking about the use of dental photography - an interesting way to keep a record of the progress of procedures that require longer than a usual period to complete, show off the work done and possibly educate millions of students worldwide. In addition, dental photography can be used by dentists to promote their practice and show their patients an example of previous cases showing off how effective work looks like when completed.

Keywords: Dental Photography, Record Maintenance, Student Education, Modern Dental Practice.

Copyright @ 2020: This is an open-access article distributed under the terms of the Creative Commons Attribution license which permits unrestricted use, distribution, and reproduction in any medium for non-commercial use (NonCommercial, or CC-BY-NC) provided the original author and source are credited.

\section{INTRODUCTION}

Digital photography has now entered in all segments of science, medicine, business, fashion design, communication and the arts and without photography it would be hard to imagine some aspect of our life. By now, if you don't have any sort of digital camera (yet if it's a point-and-shoot, a digital single-lens reflex [DSLR], or perhaps a smartphone), you might be living on a different planet. Film periods are all but gone and the need for instant photographic analysis is almost omnipresent. This is also truly the case in dentistry - from an immediate on-screen $\mathrm{x}$-ray analysis for the dentist to showing current or prospective patients how their teeth look in either the operating room or the consultation room from their point of view, to help them better understand what great dentistry could do for them.

Today there are several purposes for using dental photography; the predominant goal of digital dental photography is to accurately document the oral cavity noticeable symptoms. Other typical advantages as a sequel include legal reporting, publishing, training, patient communications, sharing with colleagues and technicians and finally marketing. Increasing of such uses strengthens and elevates the dental practice reputation, as well as increases patient care quality.

\section{HISTORY}

The background of dentistry and photography started in 1840, just as the first dental institution with the world's first photographic gallery was opened, being run by a dentist turned to photographer. As photography became an essential element of a patient's record and planning process, photography and dentistry have now been partners [2].

Photography provides the user with the ability to accurately capture patient records, activities and chart scientific observations. Alexander Wolcott (1804-1844) was influential in the development of photography. In 1840 he received the patent for his camera innovations and created a system for photographic studio.

Dr. R. Thompson and W. Elde of Columbus, Ohio, represented the first use of dental procedure with before and after photos, and an article was posted which created a new paradigm in dental diagnosis and treatment planning. More notably, the dental profession started using clinical photography as part of preparation procedures for diagnosis and care. Its role in recording cases, communicating information, and informing patients has evolved to the point that it has become crucial to decision making about diagnosis and treatment planning [2]. 
Digital imaging appeared at marketplaces in mid-1990, with digital cameras accessible. While its resolution was limited, reverberations of interest had already begun among the purists and enthusiasts. In just 10 years, digital imaging has totally replaced science and medical film photography. New technology has come up which allows things to be calculated, updated, exchanged and incorporated with just a click of a mouse into advanced communication tools. Also now the photos can be animated, included in findings and authored on websites. Certain developments in innovation and business are unimaginable [3].

\section{Reasons to use dental photography}

Presently, with the emergence of digital technologies, photography has become simpler and convenient to access. Nevertheless, for factors such as lack of understanding of photographic equipment and skill, workflow disruption and cost involved, few are reluctant to introduce them in their daily practices. Fortunately, as new innovations are increasingly evolving, the cost of the equipment is also decreasing, so any clinician can incorporate photography with minimal disruptions in their patient care into their practice.

Below are 10 reasons why dental photography should be a part of everyone's practice

1. Diagnosis and treatment planning [3-4]: Intraoral images are a significant addition to the hospital records (charting, radiographs, research models). They provide a static, in-depth look at the dentition of the patient, which is easily checked and compared with other records of the patient. All clinical case analyses require 34 views. Of the 34 opinions, 17 should be taken prior to treatment and 17 will proceed after treatment. Additional views are needed for documenting of the technique. The images are to be recorded either in manual or in TTL function. To maximize field depth all intraoral images should be captured using high F-stops.

The cosmetic standard series include the following 17 views $[5,6]$

- $\quad$ Full face $(1: 10)$

- $\quad$ Right profile view $(1: 10)$

- Tooth show at rest (1:2) (Lick lips, swallow, slightly part your lips. Tooth show at rest is critical to determine IEP)

- $\quad$ Full exaggerated smile $(1: 2)$

- Horizontal view $(1: 2)$

- $\quad$ Tipped forward $(1: 2)$

- $\quad$ Right lateral smile view $(1: 2)$

- Left lateral smile view (1:2)

- Retracted view anterior teeth closed (1:2)

- Retracted view anterior teeth slightly open $(1: 2)$

- $\quad$ Right lateral retracted view teeth closed (1:2)

- Left lateral retracted view teeth closed (1:2)
- Close-up anterior centrals view (1:1) with block-out paddle

- Close-up right lateral retracted view (1:1) with block-out paddle

- Close-up left lateral retracted view (1:1) with block-out paddle

- Maxillary occlusal views (1:2) (photograph the reflection in an occlusal mirror)

- Mandibular occlusal views (1:2) (photograph the reflection in an occlusal mirror)
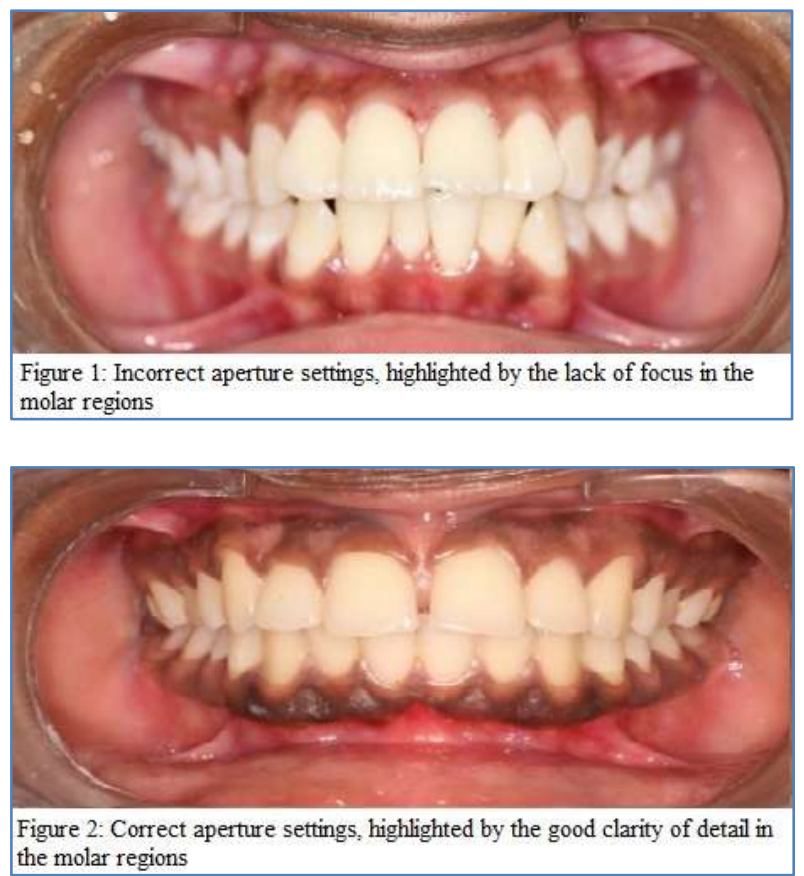

For intra-oral photography ideal aperture is set at f-32 Figure 1 and Figure 2 highlights the correct and incorrect depth of field settings.

2. Boosted awareness and communication with patients [3,4]: Visual and auditory assistance such as video clips, prototypes, and pamphlets had been available for patient education purposes so far, but none of these approaches covered the information thoroughly. Using a touchscreen display and presentation software, the photographed cases could be used to create tailored demonstration on dental procedures. Such comprehensive images showing anatomy, surgical steps, equipment and finished cases can help educate patients about the assessment and treatment proposed and thus improve their awareness and acceptance of the case.

3. Legal accounting [3, 4]: Digital (nonedited) images in their raw format may be used as evidence of legal documentation. This can benefit a victimised patient or protect a colleague who has rendered adequate treatment or can be of assistance in cases alleging misconduct.

4. For insurance purpose: Insurance providers demand periodontal charting, $\mathrm{x}$-rays, or a summary before 
issuance of benefits to the customer. So one can use a digital image to endorse a narrative.

5. Consultation with expert: Mapped X-rays and written notes were the only way of introducing out patients to other specialists. Now an entirely new aspect has been added with the images. With an over-the-phone consultation with a consultant, a full case history with high-resolution photos may be enough. Likewise, photos of the referring practitioner and their recent milestones could be transmitted or obtained so that the doctor could evaluate the condition without being actually present in the office.

6. Laboratory communication: A shade guide is most frequently used to communicate details about the character of the tooth or gingiva, hue, or colour. Most of the time, this technique is followed by demerits, such as falling short of describing the complexity of depth and shadowing a tooth. A color - corrected image will then provide the muchneeded details to produce a final reconstruction with a more accurate hue, value and chroma.

7. Professional Marketing and Ads: Pre and post images are important tools to encourage patients to embrace the care plan or to demonstrate certain particular skills $[3,4]$.

8. Professional instruction: Sometimes only documents and arrows are insufficient to explain dental principles or basic surgical procedures. A photo is good enough to justify more than a thousand words and gives rise to more value and discussion than writing.

9. Self-education/improvement: We learn a lot as professionals during our careers. Workshops and other forms of continuing education are very necessary means of education. For all of these times digital photography is a blessing.

10. Philosophy of diagnosis and work ethic: Taking time and energy to clean photography surgical sites takes patience and meticulous planning. This mentality propels us to carry out our research at the high precision rate. Therefore educating the patient in exchange for photographs helps to develop our own skills.

\section{What are the basic armamentariums we need?}

\section{Digital camera[7]}

- Compact point-and-shoot cameras or

- Digital single lens reflex.

- More the pixels, greater would be the detail of the image. In digital dental photography, minimum of 10 Mega Pixels is required.

- Intraoral cameras

\section{Camera accessories}

- Lens: Different lens types are available, and each for various uses. The lens that mostly interests us for purposes of recording and documenting are usually the macrolenses. Such lens system enables a clearer focus in the close-up images since they have a wider diaphragm and we get a higher magnification than with other armature lenses. The items and the photos are dealt with in short distances in medical and scientific documentations. Using a macrolens can help the user better focus and get clearer images $[8,9]$.

All such lenses possess mechanisms defined by the term "Diaphragm;" they comprise of sheets that let more or less light into them, comparable to the function of iris inside the human eye. The diaphragm opens to let lighter pass in with insufficient light; on the other side, if there is ample of light, the diaphragm closes to the minimum so that it can see without being blinded. The sharpness of the picture is directly influenced by the aperture size or diaphragm width. The smaller the diaphragm, the sharper the picture will be.

- Light and electronic flash systems

- $\quad$ Ring flash (Figure 3)

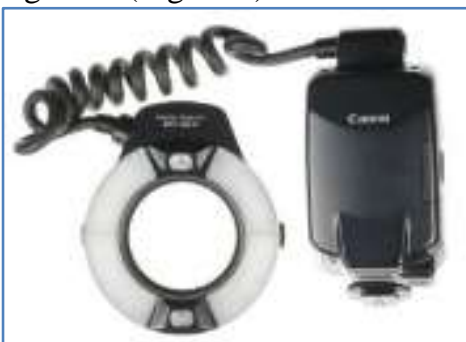

Figure 3. A typical ring flash system

- $\quad$ Point flash

- $\quad$ Twin flash (Figure 4)

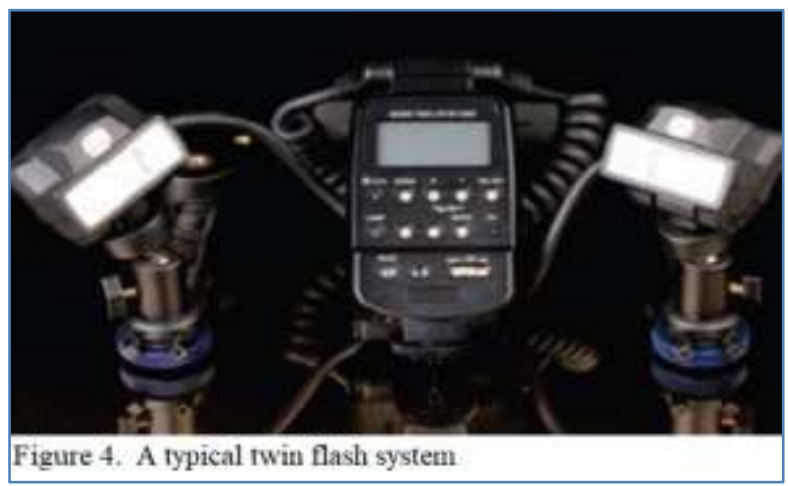

While requiring more experience and thought for proper use, the twin flash design system may offer the best combination of soft, uniform illumination because it simultaneously reveals surface detail, color transitions, translucency variations, and crack lines (Figure 5). 


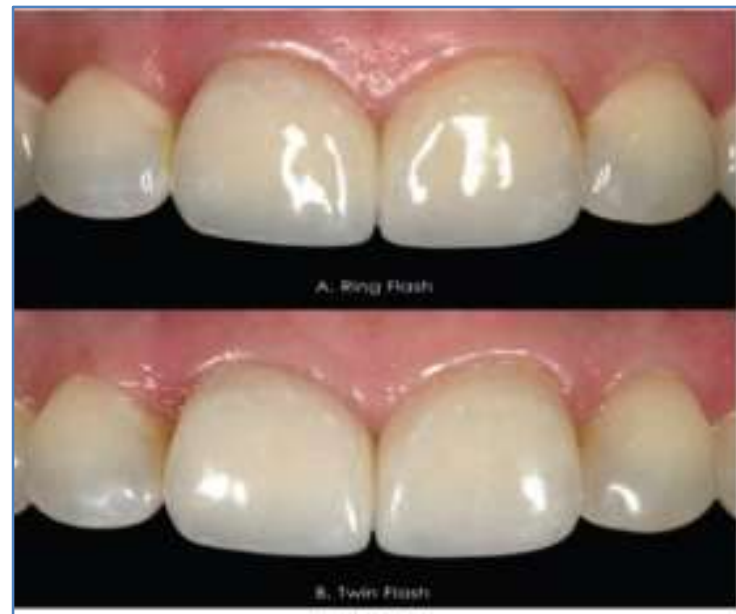

Figure 5. Note the lack of shadow and plasticity of the ring flash photo (top). The twin flash photo (bottom) shows soft, uniform illumination that reveals surface detail and color transitions.

- Memory card: for storage of data[7]

- Filter: It serves the dual purpose of lens protection and if required changing the lighting conditions[7]

- Batteries: An extra battery pack with a quick charger ensure that we never run out of battery during shoot[7]

- Camera bags: This is useful to protect the camera and be able to carry our lens, camera, and other accessories in an organized fashion[7]

\section{Clinical Accessories}

- Cheek retractors

- Columbia wire lip retractor: This combines buccal mirror and cheek retractors [7].

- $\quad$ The martin metal retractors [7].

- Intraoral mirrors: Like long-handled frontsilvered rhodium-coated glass mirrors [7].

- Black background/contrasters [7].

\section{Other accessories equipment}

- Plastic or glass spatula

- Disposable plastic spoons

- Dental mirrors

- Gauze strips

- Air syringes or aspirators.

\section{Guidelines for clinical photography}

Standardization, i.e. uniform lighting, aperture settings, patient orientation, angle, dynamic range and background, is very important for achieving a successful digital dental image. Photographs should be properly preserved and displayed for use in publications [10]. For all patients, different views should be taken such as frontal view that combines full facial appearance and whole dentition. Certain views for esthetic purposes, such as lateral and oblique lateral, occlusal mandibular maxillary and a three-quarter view of the head [11]. Photography can be broken down into three broad fields, namely: patient preparation, ambient and intraoral locations, camera preparation [12].

\section{Use of digital photography in periodontics:}

Hausmann[13] in 2000 reviewed radiographs and digital imaging in periodontal practice. His review first considered the terminologies "accuracy" and "reproducibility" in imaging, and covered how to produce standardized Photographs and how to manage serial photographs once these have been digitized. He noted that subtraction photography (being able to tell differences in structures recorded between one standardized digital or digitized photograph and another) could be of great use to the practising periodontist.

There has been a substantial increase in the demand and availability of postgraduate dental courses available in INDIA over the last few years. Such courses usually involve one or more evaluated components like case presentations as well as the representation of a clinical research portfolio (Figure 6). Direct measurement of gingival recession using a periodontal probe as record finding for comparing pre and post treatments values[14] is very helpful (Figure 7).
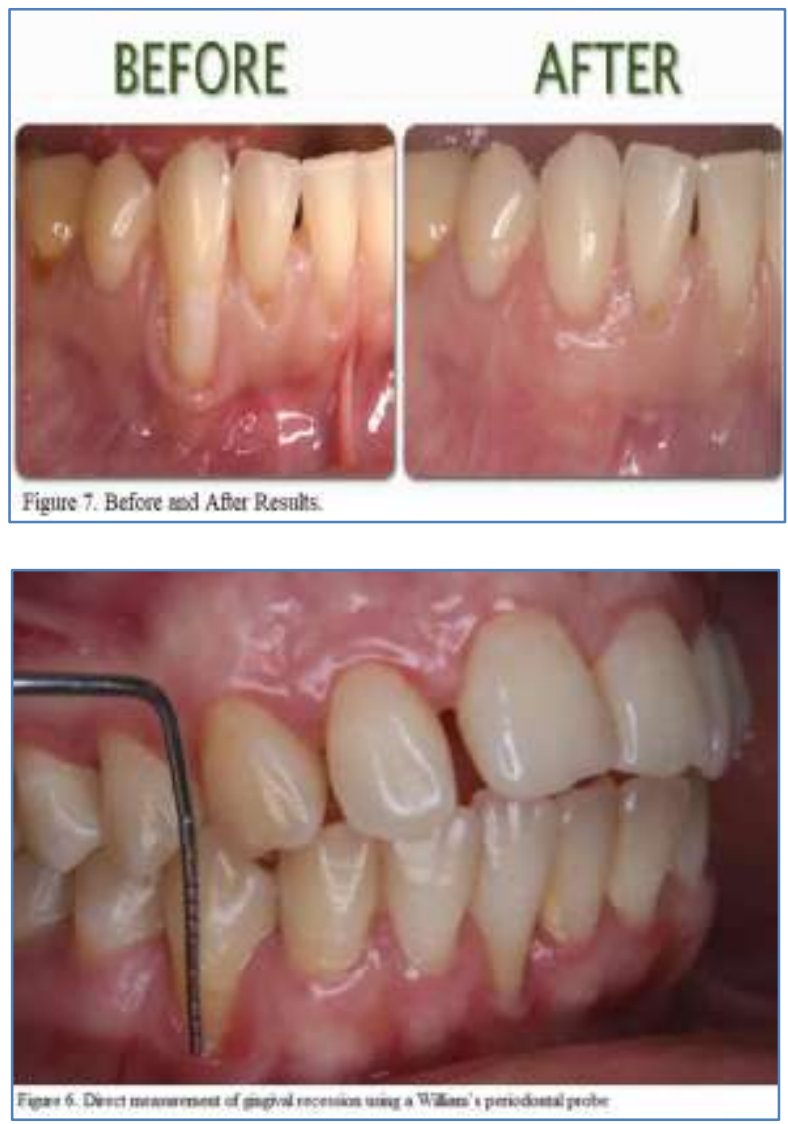

\section{CONCLUSION}

Dental photography is a creative, healthy and easy to use tool for capturing the outcomes after a dental operation is complete. This is a tool that can be 
used for a variety of purposes including promotion, education and recording of the outcomes achieved. Dental photography provides an incentive for selfpromotion, and awareness not to mention the ability for patients to see progress from a particular viewpoint. The modern dental photography approach is some kind of macro photography with the rise of digital cameras; photography has become simple and affordable way to educate and record our patients. Digital photographs can be conveniently saved and held for legal or academic use in future. This article deals with the bare minimum a dentist requires, or rather should learn, before entering the fascinating world of digital clinical photography.

\section{REFERENCES}

1. Ahmad. Digital dental photography. Part 2: purposes and uses. British Dental Journal. 2009; 206:459-464.

2. Galante DL. History and current use of clinical photography in orthodontics. J Calif Dent Assoc. 2009;37:173-4.

3. Bengel W. Mastering Digital Dental Photography. 1st ed. New Maiden, Surry (UK): Quintessence Publishers; 2006.

4. Yoo A. 10 reasons why dental photography should be an essential part of your practice. Dent Econ. 2014;104:1-7.

5. Geissberger M. Esthetic Dentistry in clinical practice. Wiley-Blackwell Publishers; 2010.

6. Desai V, Bumb D. Digital dental photography: A contemporary revolution. Int J Clin Pediatr Dent. 2013;6:193-6.
7. Sreevatsan R, Philip K. Digital photography in general and clinical dentistry-technical aspects and accessories. Int Dent J Stud Res. 2015;3:17-24

8. Manjunath SG, Raju Ragavendra T, Setty SK, Jayalakshmi K. Photography in clinical dentistry A review. Int J Dent Clin. 2011;3:40-3.

9. Chandni P, Anupam S, Nitin S, Shikha G. An overview on dental photography. Int J Dent Health Sci. 2016;3:581-9.

10. Nayler JR. Clinical photography: a guide for the clinician. J Postgrad Med. 2003;49(3):256-262.

11. Schaaf H, Malik CY, Howaldt HP, Streckbein P. Evolution of photography in maxillofacial surgery: from analog to 3D photography-An overview. Clin Cosmet Investig Dent. 2009; 1:39-45.

12. Recommended Guidelines for Clinical Photography. Academy of Laser Dentistry's Annual Conference $@$ 2012. Guidelines for Clinical Photography; 2013. Available from: http://www.laserdentistry.org/callforabstracts /2013/Guidelines_For_Clinical_Photography_2013 .pdf.

13. Hausmann E. Radiographic and digital imaging in periodontal practice. J Periodontol. 2000; 71: $497-$ 503.

14. Fageeh HN, Meshni AA, Jamal HA, Preethanath RS, Halboub E. The accuracy and reliability of digital measurements of gingival recession versus conventional methods. BMC Oral Health. 2019 Dec;19(1):1-8. 